\title{
The food security continuum: a novel tool for understanding food insecurity as a range of experiences
}

\author{
Sheryl L. Hendriks ${ }^{1}$
}

Received: 30 September 2014 / Accepted: 25 March 2015 / Published online: 24 April 2015

(C) The Author(s) 2015. This article is published with open access at Springerlink.com

\begin{abstract}
The current lack of consensus on the relationships between hunger, malnutrition and food insecurity frustrates efforts to design good policies and programs to deal with the many problems. Disputes over terminology distract from the need for urgent action. This paper argues that our understanding of food insecurity is incremental: it develops as new research in a variety of food-deprived and nutrition-deprived contexts reveals causes, experiences and consequences and how they are interlinked. If we are to improve beneficiary selection, program targeting and intervention impact assessment, it is vital to coordinate our new understandings. The paper brings convergence to our understanding of food insecurity by introducing a new framework that visualizes levels of food insecurity, and the concomitant consequences and responses, as a continuum. Some potential benefits of using the continuum as a diagnostic tool are increased focus on less extreme but nevertheless urgent manifestations of food insecurity, more accurate targeting of interventions and better follow-up, and improved accountability for donor spending.
\end{abstract}

Keywords Food security $\cdot$ Food insecurity $\cdot$ Malnutrition . Under-nutrition $\cdot$ Hunger $\cdot$ Starvation $\cdot$ Obesity $\cdot$ Measurement

\section{A complex problem}

Food insecurity is a problem with multiple manifestations. Multiple contributing causes - social norms, individual

Sheryl L. Hendriks

sheryl.hendriks@up.ac.za

1 Institute for Food, Nutrition and Well-being, University of Pretoria, PBag X20, Hatfield, Pretoria 0028, South Africa behavior and stages in the human life cycle, food availability and quality - make it a problem requiring comprehensive approaches. The difficulty we face is in bringing convergence to our understanding of the varied experiences of human deprivation so as to improve our response to the problem.

The concept of "food security" first began to attract attention in the 1940s and is now widely used in designing, implementing and evaluating humanitarian emergency and development policies and programs. Today the universal definition of "food security", accepted by the highest level of global governance on food security, the Committee on World Food Security (CFS), describes it as a situation where "all people, at all times, have physical and economic access to sufficient, safe and nutritious food to meet their dietary needs and food preferences for an active healthy life" (CFS 2012 as per the FAO 1996 definition).

However, the usefulness of the concept is constrained by the plurality of ways of understanding the causes and consequences of food insecurity, and the effects of economic, social, political and environmental interventions. Further complicating the issue is the transdisciplinary nature of the food security research field: the experts from different traditional disciplines working together are giving us a more nuanced understanding of the concept but also potentially muddying the waters. Assorted discourses and paradigms compete for domination, leading to conflicts over terms and concepts (Lang and Barling 2012; Candel 2014). The terms "food security", "nutrition security", "food security and nutrition" and "food and nutrition security" are used interchangeably, and some scholars assert a hierarchy among these terms. The proliferation of terms initiated a discussion at the Committee on World Food Security annual meeting in 2012 (CFS 2012). The CFS input note on "coming to terms with terminology" (UNSCN 2012) sets out clearly the origins and development of the contentious terms. But despite a CFS resolution on the use 
of the terms (CFS 2012), they are still being used interchangeably. This does not make for clarity of understanding or effective policy and program development.

The question of how people experience deprivation continues to perplex us and hamper our efforts to monitor food insecurity situations (Headey and Ecker 2013). Much food security research has attempted to find causal explanations for how material and structural poverty lead to deprivation that manifests in multiple ways. The conclusions often reflect the background and orientation of the researchers. Our plurality of backgrounds (agronomy, economics, sociology, health, nutrition, among others) influences our understanding of what causes food insecurity and consequently of what we must do to deal with it.

The economic, social, environmental and political systems related to food are inextricably inter-connected: eliminating one cause of food insecurity may bring to light a more deeply rooted cause of which the original insecurity may have been a symptom. For example, we might give cash to a poor community to buy food, only to find that lack of cash was a symptom of another problem, such as a lack of local livelihood opportunities. The contributions of different disciplines are needed to deal with multi-layered problems such as this. But theoretical disagreements may distract from the problem. One such disagreement concerns the direction of causality: there is little consensus as to whether food insecurity is a consequence or a predictor of inadequate livelihoods and poor nutrition (Campbell 1991). Pangaribowo et al. (2013) offer a third argument: that food security is an aim in itself, not just a prerequisite for adequate nutrition.

This paper argues that the debates lose direction when they fail to differentiate between the risk factors for food insecurity, food insecurity as a phenomenon in itself and the consequences of food insecurity. There seems to be no end to the overlaps and interactions between the categories. Failure to define the topic leads to confusion when it comes to policies and interventions and how to measure their impact.

How we understand and define food insecurity determines how we measure it (Hendriks and Drimie 2011; Coates 2013; Candel 2014). The measurement can take into account quantitative, qualitative, psychological and social or normative constructs of the experience of food insecurity, qualified by their "involuntariness and periodicity" (Campbell 1991, p 410). Competing approaches to food insecurity measurement have emerged over time and no generally accepted framework exists on which to base the measurement. Despite numerous attempts during the 1990s (see Hendriks 2005 and Headey and Ecker 2013 for reviews of these), measuring food insecurity still evades simplification. Each measure both captures and neglects phenomena intrinsic to the concept of food security, thereby subtly creating priorities among food security interventions (Barrett 2010).
Very few measurement systems are based on a full definition of food insecurity. Pinstrup-Andersen (2009: 137) says that if we interpret the FAO definition quoted above "to mean that the nutritional needs of each individual have to be met for the person to be food secure, the FAO estimate of 800 to 900 million under-nourished people would be a gross underestimate of the prevalence of food insecurity". He notes also that "if the estimate of two billion iron deficient people is correct, that number would be the lower bound for the number of food insecure people in the world". He argues that what is at issue is "whether the FAO definition of food security, that is now widely accepted, can be used to disaggregate the concept into different kinds of food insecurity depending on the nature and severity of the problem and the type of solution required".

Understanding the problem of food insecurity is a cumulative process. The following two sections describe how our knowledge has developed incrementally in response to deepening theoretical discourse and also research findings about experiences, causes and consequences. The first of these two sections looks at our incremental theoretical understanding of the four dimensions of food security set out in the World Food Summit definition, availability, accessibility, utilization and stability (FAO 1996), and how these have influenced measurement and interventions. The second discusses how ongoing research has led to an incremental understanding of the experience of human deprivation and the relationships between hunger, under-nutrition, malnutrition and food insecurity. In the next section the author brings together the theoretical and human experience of food security and presents a new framework in which levels of food insecurity are visualized as a continuum. This novel tool combines elements of the triple burden into a single continuum of experiences across emergency and non-emergency as well as obesogenic contexts. The penultimate section discusses some advantages to the application of the continuum for understanding and dealing with food insecurity. The paper concludes by recommending that this diagnostic tool could help improve the accuracy of targeting of interventions, better follow-up and improved accountability for donor spending.

\section{Our incremental understanding of the dimensions of food insecurity that influence measurement and intervention design}

Early conceptualization of food insecurity (prior to the 1980s) relied on a belief that inadequate food supply led to food insecurity. The solution was therefore to produce more food. Consequently, availability of sufficient food was monitored using food balance sheets, from which estimates of food available to meet per capita energy needs were derived (Webb et al. 2006; Pinstrup-Andersen 2009). The physiological consequences of food shortages were measured and monitored 
anthropometrically. During this period, food security interventions focused on food aid shipments to meet immediate needs and agricultural production strategies to increase food supplies in the long term. But despite increases in global and national food supply following the 1974 world food crisis, undernutrition rates remained stubbornly high in many parts of the world (Barrett 2010).

The work of Sen in the 1980s led to a widespread awareness that access to food was as essential as having a positive national food stock balance. Sen advanced the understanding of food insecurity when he pointed out that people experience food deprivation because they have difficulty accessing it and not necessarily because it is not available in the marketplace. In his work on poverty Sen viewed food security as a household purchasing power issue affected by access to income and other resources (such as transfers and gifts), market integration, price policies and market conditions (Sen 1981). Food security measurement consequently shifted to identifying subjective experiences of hunger and "coping" strategies as determinants of food security. Consequently, during the 1990s, intervention focus shifted to poverty reduction, food price stabilization and social protection policies (Webb et al. 2006; Barrett 2010).

However, Renzaho and Mellor (2010) warn that it is misleading to measure food security through coping strategies without taking into account the social, cultural, and political contexts in which they occur and that to look at food insecurity solely from the perspective of availability or access to food, without taking into account the importance of how food is used, "paints an incomplete picture". The term "utilization" - one of the four dimensions of food security in the FAO's World Summit 1996 definition - reflects concerns about whether people make good use of the food to which they have access. The concept of utilization, i.e., nutrition, covers dietary quality, especially micronutrient deficiencies, food safety and the ability to absorb and metabolize essential nutrients (Barrett 2010).

It was during the 1990s that the emphasis fell on utilization as the key to attaining food security. Micronutrient deficiencies increase the risk of both chronic and infectious diseases, aggravate the effects of disease and lead to irreversible loss of cognitive and physical function, especially during a child's first 1000 days (from conception to the age of two) (Barrett 2010). Increased awareness of the scale and impact of micronutrient deficiencies led to a new focus on "hidden hunger" and the importance of nutrition-focused interventions to break the cycles of poverty that perpetuate food insecurity. Mere availability of food - at national or household level - does not ensure access to an adequate diet for all citizens. Health and well-being depend on a diverse diet that provides adequate quantities of macro and micro nutrients. Issues of nutritional quality, food safety, access to safe drinking water and sanitation became important in the design of food security programs, with the health sector becoming a major partner in such programs. Nutrition-sensitive and nutrition-specific programs have grown in popularity since the turn of the century. They initially included micronutrient-focused interventions (fortification, supplementation and biofortification) and food-based interventions such as those that support household gardens. The necessity for nutrition-sensitive agricultural interventions became particularly apparent after the global food crisis of 2008/2009 (Frongillo 2013).

Measurement of food security related to utilization is based either on dietary quality (food consumption and dietary diversity) or biochemical analysis of the effects of food consumption. Both are relatively expensive. Moreover, nutrient requirements are individually determined and depend on, among other things, the sex and age of each individual. It is therefore difficult to generalize consumption and nutrition data across populations and the data cannot simply be aggregated at household or national levels as has been done with dietary energy intake in the past (Coates 2013). Such simplification ignores dietary quality. For example, stunting levels of young children can be aggregated at household level and across populations. However, nutrition is only measured at the individual level. Therefore, it cannot be said that a household is well nourished unless all members of the household meet all the criteria for sound nutrition specific to their age, weight, height, sex and level of activity. In the past, energy intake was simply used against referenced standards and thresholds established against standard deviations above or below the norm. Moreover, energy intake is only one requirement for sound nutrition.

These first three food security dimensions - availability, access and utilization - are hierarchical in nature: food availability is necessary but not sufficient for access, and access is necessary but not sufficient for utilization (Webb et al. 2006). However, all three dimensions depend on stable availability, access to food supplies and the resources to acquire adequate food to meet the nutritional needs of all household members throughout their life cycle. To date, very little food security measurement research has focused on the stability dimension of food security, although more recent attention to the concept of resilience may offer measurement and intervention options.

Our expanded knowledge of the link between short-term shocks and long-term development has aroused widespread interest in how people build resilience to adversity (Barrett and Headey 2014). To understand this we need to look at how people cope with and recover from the social, economic and environmental stresses and shocks that lead to hunger and malnutrition (Barrett and Headey 2014). Resilience interventions seek to help households anticipate and deal with stresses, absorb shocks, allocate resources to more profitable enterprises, and improve their chances of escaping poverty (Browne et al. 2014). 
Along with increased interest in the concept of resilience, a parallel stream of literature at the turn of the millennium focused on measuring vulnerability (Brown et al. 2014). The terms "vulnerability" and "food insecurity" are often used interchangeably. In order to differentiate them, we should note that food insecurity is a phenomenon whose severity fluctuates, whereas vulnerability is the propensity to fall, or stay, below a food security threshold. In other words, "vulnerability" refers to the ex ante probability of falling or remaining below a specific threshold, while "food insecurity" is the current or ex post measure relative to the threshold (Løvendal and Knowles 2005). However, no standard exists that defines this threshold, and the terms continue to be used loosely, masking the realities of daily deprivation for individuals and communities. Alinovi et al. (2010) argue that the multidimensionality of food security and the unpredictability of shocks make vulnerability measures ineffective, and a lack of longitudinal empirical data on various risks constrains our analysis of trends.

\section{Our incremental understanding of the relationships between hunger, under-nutrition, malnutrition and food insecurity}

Just as our understanding of food security as a concept has followed an incremental development path, so too has our understanding of food insecurity as a lived experience. With time and more research we have come to a better understanding of the ways that various states of deprivation - hunger, undernutrition, malnutrition and food insecurity - are related. Up to the late 1990s, discussions and research in the field of food security focused on humanitarian crises and famines. However, the last famine in Europe was in the 1940s, in east Asia in the 1960s and in south Asia in the 1970s (Devereux 2009). North Korea faced a famine in 1990 but it was the product of a unique political economy rather than a typical food shortage (Devereux 2009). Four famines in Africa that claimed hundreds of thousands of lives between 1999 and 2012 (Ethiopia, Malawi, Niger and the Horn of Africa) challenged earlier beliefs that famine was primarily related to food shortages. Unlike earlier famines in other parts of the world, these African famines resulted not from a shock (the onset of conflict or a food shortage) but rather from the failure of long-term development processes (Gross and Webb 2006). Even after political stability and economic growth have been restored, the impact of a famine lingers, leaving a nation carrying a burden of lost productivity.

But we do not need to look at the extreme case of a famine to find examples of food deprivation. If we look at developing economies such as Brazil and India, we can see that economies can grow without proportional gains in the nutritional status of the poor (Gross and Webb 2006). Moreover, most deaths in children below the age of five do not happen in acute emergencies - they happen in relatively stable countries (Gross and Webb 2006). Of all food-deprivation-related deaths worldwide in 2004 , only $8 \%$ were caused by humanitarian disasters, while $92 \%$ were associated with chronic hunger and malnutrition (Gross and Webb 2006, citing the FAO State of the World Food Security, 2006). The plight of millions of undernourished children in non-emergency zones poses a significant disaster risk unless longer-term coordinated development efforts help avoid disaster (Gross and Webb 2006). Such situations (as was the case in the Niger famine) are a springboard for a sudden leap in mortality when a disaster strikes. Gross and Webb (2006) describe the situation as "a long-running silent emergency" that lays the foundation for future disasters.

Barrett (2010) argues that most severe food insecurity is typically associated with natural and civil disasters. Yet most current food insecurity is not associated with catastrophes but with chronic poverty. Recent attention to development failure helps us understand food insecurity as the consequence of structural poverty and inequality (Hendriks 2013). Structural food insecurity is often the result of extended periods of poverty, lack of assets and inadequate access to productive or financial resources (Pangaribowo et al. 2013). Even in the developed world, hunger is linked to poverty, a situation where there are inadequate resources to obtain food. Poverty is therefore a significant predictor of hunger and food insecurity. People experience food insecurity when they are uncertain about their future supply of and access to food, when their intake (of energy as well as macro and micro nutrients) is inadequate for a healthy life, or when they are obliged to resort to socially unacceptable means of acquiring food. In these situations of food insecurity, hunger and malnutrition are possible, though not necessary, consequences (Frongillo 2013).

The magnitude and ubiquity of such deprivation (across emergency and non-emergency zones) is a significant cause for concern, although the percentage of children who are stunted has been decreasing since 1990. In 2012, $56 \%$ of all stunted children were in Asia and $36 \%$ in Africa, $67 \%$ of all underweight children were in Asia and $29 \%$ in Africa, and $71 \%$ of all severely wasted children were in Asia and $28 \%$ in Africa (UNICEF et al. 2013). Barrett (2010) states that over two billion people worldwide suffer from micronutrient deficiencies - double the number that suffer from inadequate dietary energy. Evidence from many countries shows a weak correlation between energy deprivation and anthropometric indicators of malnutrition - both at the national aggregate and at household levels, emphasizing the importance of overall diet quality (Headey and Ecker 2013). Micronutrient deficiencies increase the risk of both chronic and infectious disease, aggravate the effects of disease, and lead to irreversible loss of cognitive and physical function, especially during the crucial period from 9 to 24 months of age. These irreversible effects foster persistent poverty, thus worsening the consequences of food insecurity. 
Prior to the mid-1990s the terms "hunger" and "famine" were frequently used interchangeably (Webb et al. 2006), as were "hunger" and "food insecurity" in the 1980s and 1990s (Campbell 1991). Only in 1999 was the term "food security" used in US empirical assessment tools. Until then, the focus had been on measuring domestic hunger (Wunderlich and Norwood 2006). The change in focus was prompted by the 1984 Report of the President's Task Force on Food Assistance in which it was stated that hunger in the US may not be prolonged enough to manifest in clinical symptoms and affect health (Wunderlich and Norwood 2006). Consequently, hunger in the first world is largely "hidden" and seldom results in overt signs of malnutrition (Riches 1998; Carlson et al. 1999). Both food insecurity and poverty are predictors of nutritional deprivation (Bhattacharya et al. 2004). The term "food insecurity" therefore means more than material deprivation that leads to poverty and more than the presence of hunger; it also covers nutritional deprivation.

However, hunger and malnutrition are possible but not necessary consequences of food insecurity. Differentiating between biological and socio-economic factors helps us to understand more about the relationship between hunger and malnutrition (Campbell 1991). Te Lintelo et al. (2014: x) define hunger as "the result of an empty stomach" which in turn results from "having insufficient income or social and economic entitlements to access food". Hunger is usually measured in terms of a lack of food - typically as unavailability of food and insufficient energy intake (Masset 2011). Some hunger measures focus on the consequences of hunger - primarily seen as growth faltering and failure, determined through anthropometric measures - but hunger can have other consequences: poor cognitive ability, low productivity, morbidity and mortality (Masset 2011). Some form of under-nutrition is an inevitable consequence of hunger. Consequently, under-nutrition is related to but different from hunger. Under-nutrition can also exist in the absence of hunger: it can be caused by factors unrelated to the quantity of food, such as poor diet quality, or diseases causing malabsorption of nutrients.

Work on understanding famine and HIV/AIDS in Africa in the 1990s has given us a deeper understanding of coping strategies and how households behave when facing hunger (Rugalema 2007). Research has also shown that food needs compete with other needs and that trade-offs involving foods are sometimes made to ensure long-term livelihoods (De Waal and Whiteside 2003; Rugalema 2007). Radimer et al. (1990) identified four aspects common to the experience of food insecurity:

- A quantitative aspect of not having sufficient food

- A qualitative aspect related to the types and diversity of food

- A psychological aspect manifesting as feelings of deprivation or restricted choice and anxiety over food on-hand in the household

- A social or normative aspect in which individuals evaluate their own situation in terms of generally accepted social norms such as the number of meals per day or socially acceptable ways of obtaining food.

Recent work by Frongillo (2013) has further advanced our understanding of the experience of food insecurity. He points out that not all the effects of food insecurity are directly related to food. Worry and anxiety, feelings of alienation, deprivation and distress, and adverse changes in family and social interactions can also lead to poor physical and mental health and weight loss. Understanding the connections between hunger and undernutrition and these non-food aspects of food insecurity gives us a clearer picture of the complex ways that poverty leads to food insecurity, which in turn leads to poor diet quality and quantity, inadequate nutrition and poor health (Frongillo 2013).

However, hunger and under-nutrition are not the only possible consequences of food insecurity. Since 1995 there has been considerable debate about the link between food insecurity and obesity. The paradox (Caballero 2005) that poverty can make a person obese is being explained now, as we reach a better understanding of the mechanisms of food insecurity. We now understand that poverty is a significant predictor of food insecurity and that food insecurity is a risk factor for poor diets. Until recently, overweight was inevitably blamed on excessive food intake (Townsend et al. 2001). Frongillo (2013) notes that the belief that food insecurity causes only weight loss and not gain is strongly held and often comes with negative sociological and political overtones regarding the reasons why people live in poor conditions. But poverty and food insecurity are both forms of material deprivation that have a range of harmful consequences that could well include excess weight gain (Frongillo 2013).

The notion that there was a relationship between hunger and obesity in the US was first proposed by Dietz (1995: 766), who deduced from his 1994 case study that "food choices or physiologic adaptations in response to episodic food shortages could cause increased body fat". Following this initial awareness, more studies - not only in the developed world, but also in developing countries - showed that adults (especially women) from low income families were more likely to be overweight than those from better-off households (Townsend et al. 2001). Food insecurity-influenced weight gain can be caused by disordered eating patterns. Experiences and fears of food restriction are likely to affect the quality of diet and eating behavior in many ways (Sarlio-Lähteenkorva and Lahelma 2001). Because a poor household spends a major proportion of its income on food, prices have a strong effect on what foods it selects (Caballero 2005). Globalization of the food system has increased the availability of mass-produced, low-cost, energy-dense and nutrient-poor foods. Because children's nutrient needs are proportionately higher than those of adults, the effect of such foods may be to adversely affect a child's growth but provide sufficient energy for an adult to gain excess weight (Caballero 2005). These effects are not limited to the wealthy; levels of 
obesity have risen in both developing and developed countries across the world (Stevens et al. 2012; Popkin et al. 2012).

Our new understanding of the way that under-weight and over-weight are related has changed the way we respond to food insecurity. Interventions have shifted from filling the dietary energy gap to improving dietary quality. This demands a broader approach to addressing food insecurity across a spectrum of experiences and outcomes. Availability, access and utilization depend on the broader food system, which in turn depends on the social, economic and political environment. Households are exposed to a range of covariant and idiosyncratic shocks, such as climatic fluctuations, conflict and disease, or job losses and food price increases, that can disrupt food availability, access and utilization (Webb et al. 2006). Interventions therefore need to be very specific and appropriate to the particular context.

Because micronutrient deficiencies reduce well-being and productivity, under-nutrition undermines human capacity and places strain on the state's health and welfare system. We are only now beginning to understand the consequences of an increasing proportion of over-weight people (in both developed and developing countries) in terms of loss of productivity and health care costs. Future food security policies and programs will need to consider the full continuum of food insecurity experiences and consequences if they are to deal with the "triple burden" of hunger, nutrient deficiencies and obesity comprehensively.

\section{Food insecurity as a continuum}

It is internationally recognized that there is no "perfect single measure that captures all aspects of food insecurity" and that food insecurity is not a homogeneous condition easily measured in economic, energy-availability or anthropometric terms (Webb et al. 2006, p1405S). Much food security research since the 1974 global food crisis has focused on understanding the causes of food insecurity in a variety of contexts or developing indices for measuring it. Yet, after decades of intensive discussion and indicator development, we still do not have a universally accepted food security measurement system that we can apply across emergency and non-emergency contexts and use to develop interventions. One reason for this is the difficulty we experience in getting a grip on all the various strands of the problem. If we are to target our interventions effectively, we need to define the experiences, causes and consequences of food insecurity clearly and understand how the multiple dimensions reinforce each other and compound the problem. Such clarity will help us to predict more accurately who is most likely to be adversely affected by shocks, design more appropriate programs, and determine whether our interventions are working for the intended beneficiaries.

A prerequisite for determining the state of food insecurity is to create a scale against which to measure it. Food insecurity is not a single experience but a sequence of stages reflecting increasing deprivation of basic food needs, accompanied by a process of decision making and behavior in response to increasingly constrained household resources (Rose et al. 1995). It is a continuum of experiences ranging from the most severe form, starvation, to complete food security, defined as a state in which all the criteria of the FAO (1996) definition of food security "physical and economic access to sufficient, safe and nutritious food to meet ... dietary needs and food preferences for an active healthy life" - are met and there is no worry about future food supply to meet these criteria (Fig. 1). A point to note is that the food (in) security status of an individual or household is not static and can change over time. Many current assessments do not take this into account. It is part of the difficulty in measurement.

Changes in food security status can be temporary, cyclical, medium-term or long-term. These changes may be caused by sudden reductions in the ability to produce or access enough food to maintain the necessary quantity and quality of dietary intake. Food insecurity is usually seasonal or regular (over periods of a month) but may also be aperiodic, i.e., associated with temporary unemployment, episodes of ill health, or other recurring adverse events (Vaitla et al. 2009; Barrett 2010). Such events lead to changes in the food security status of individuals and households and a resultant shifting along the continuum, becoming sometimes more and sometimes less food secure.

Typically, households anticipate such possibilities and routinely take precautions to mitigate their risks. They diversify or increase their options for obtaining food, buffering themselves against shocks that adversely affect or eliminate certain options, or compensating for the loss of one option by replacing it with another. In so doing, they may reduce their risk of more severe food insecurity. However, these traditional ways of coping may erode a household's capacity to withstand shocks and push it further towards food insecurity. Food security interventions should aim not only to save people from dropping back into worse states of food insecurity but to move them along the continuum towards food security and resilience.

Taking what we know about household behavior in response food to shortages (caused by production failure, entitlement failure or inadequate purchasing power), we can

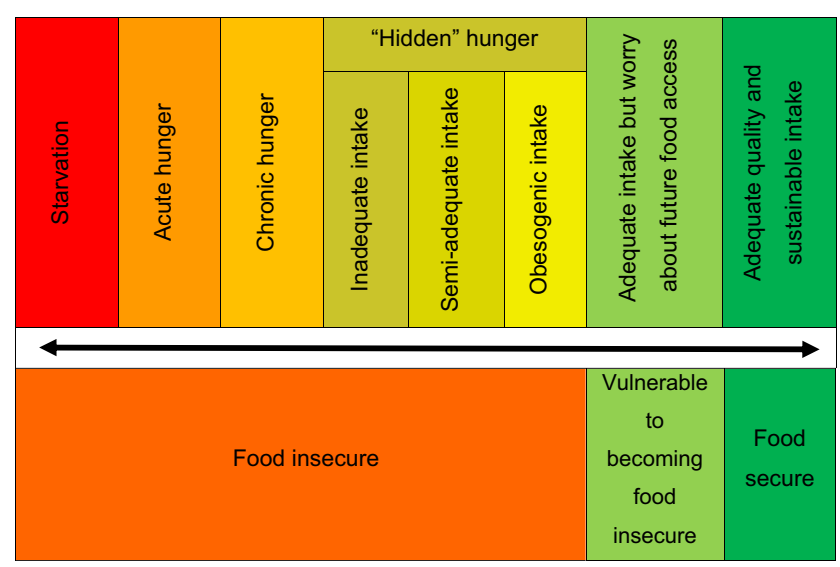

Fig. 1 The food security continuum 
identify a continuum of experiences of food insecurity (Fig. 2). Research has shown that the first sign of possible food insecurity is worry over future food supplies or the means to acquire food (Maxwell 1996; Maxwell et al. 1999). If the threat becomes a reality, households start adopting what Barrett (2010, p827) calls "precautionary" strategies.

When the first signs of real food shortages are seen, households find ways of cutting food consumption (Maxwell 1996; Maxwell et al. 1999). These start as subtle changes such as reducing variety, adding ingredients to "stretch" meals (such as bulking up meat dishes with legumes or other vegetables), using cheaper ingredients (such as bones instead of meat) or switching to cheaper foods. Such strategies may compromise the nutritional value of the food. In some cases the strategy is to use fewer processed foods, even though they require more fuel and effort to cook. In other cases it is to consume energy dense "fast foods", if these are easily accessible, as they often cost less than healthy food (Caballero 2005). Another strategy is to skip meals, but choose more energy-dense foods to prevent hunger and consume food in excess when money is again available (Sarlio-Lähteenkorva and Lahelma 2001). Where such practices negatively affect nutritional status, households and individuals will slip further into food insecurity.
Subtle consumption reduction and dietary quality compromises may lead to "hidden hunger" as a result of micronutrient deficiencies that are not easily identifiable other than by biochemical analysis. The impact of even small reductions in food and micronutrient intakes can be devastating for the fetus, young children, people whose health and nutritional needs are high (such as pregnant and breast-feeding mothers) and people whose health is already compromised (such as those who are underweight, malnourished, infirm or elderly). As mentioned above, not all such consumption compromises lead to weight loss. Weight gain that results from a poor diet is "collateral damage an unintended side effect of hunger itself" (McMillan 2014).

At each step towards the insecure end of the continuum, the chances of regaining the former state without assistance are reduced. If food shortages continue or worsen, households will continue cutting portion sizes and skipping meals. They are likely to sell off non-productive assets to buy food, reducing the asset base - an essential element for recovery and resilience (Maxwell 1996) - and heading further in the direction of chronic food insecurity. Continual inadequate intake leads to stunted growth in children and significant productivity losses for all household members. Stunting in early childhood impairs development and limits potential (Alderman
Fig. 2 Continuums of food insecurity, coping strategies and interventions. *Proportion of children six months to five years old who are below $80 \%$ of the median or below $-2 \mathrm{Z}$-score for weight-for-height (wasting), height-for-age (stunting) or weight-for-age (under-weight) (WHO 2010)

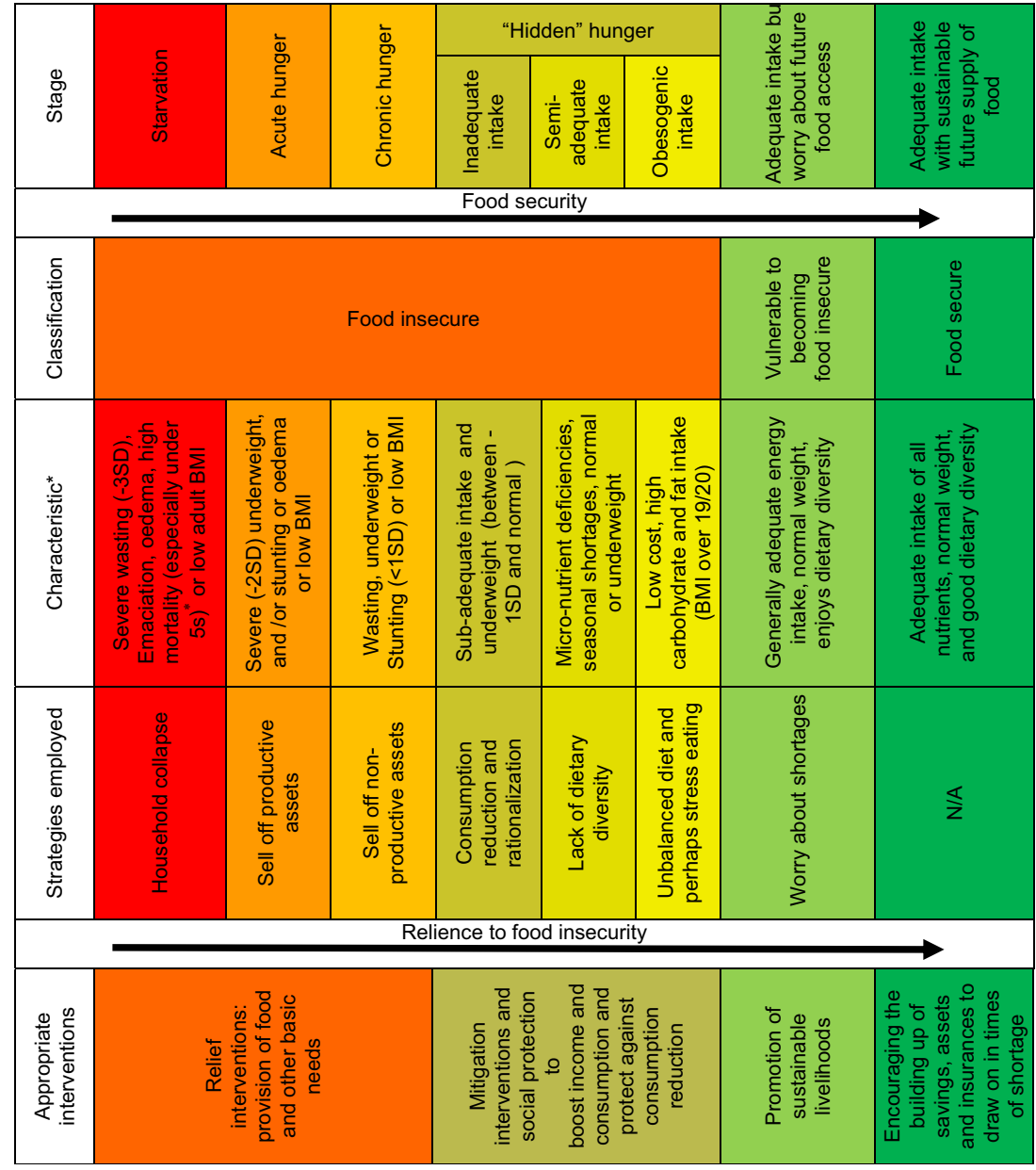


2009). People whose food intake is inadequate are more susceptible to illness, which further compromises health and nutrition. Clinical signs of undernourishment will be evident among the chronically food insecure. At this stage, people need direct access to food to enable them to raise their productive capacity. Chronic food insecurity can only be overcome by long-term development measures to address poverty, such as improved access to productive resources and expanded provision of public services (Pangaribowo et al. 2013).

Acute food insecurity is characterized by acute hunger. For people at this point on the continuum, hunger is a daily reality. Households may sell off productive assets to buy food, compromising their future livelihood opportunities and chances of recovery (Maxwell et al. 1999). Here, severe forms of under-nutrition are common, including stunting, wasting and kwashiorkor. Households may resort to reducing household size by sending members to live with relatives (Maxwell et al. 1999). These households need emergency assistance.

Starvation is the extreme experience of food insecurity. When severe hunger is widespread, a famine is declared (Howe and Devereux 2004; Devereux 2009). Extreme manifestations of under-nutrition may appear, such as severe wasting and marasmus. Households may relocate or collapse. Death becomes a possibility, especially for young children.

Classifying the severity of an experience of food insecurity by quantifying the intensity and magnitude of the deprivation is important for creating policies and designing emergency, mitigation and development programs (Howe and Devereux 2004). In Howe and Devereux's famine scale, "severity" refers to the intensity of food insecurity at a particular point in time and "magnitude" to the aggregate impact of the crisis on the affected population. Figure 3 shows a variety of possible scenarios along the food security continuum. Food insecurity may be severe and widespread or severe and individual. Interventions will differ according to the scale and nature of the problem and also according to the availability of the resources required to move individuals and households along the path towards food security.

Picturing food insecurity as a continuum makes it clear that realizing the right to food is a progressive process. Various kinds of help can be provided, such as supplying food and ensuring that basic human needs are met, protecting access to food and the means to acquire food and promoting sustainable livelihoods. For households experiencing acute food insecurity or starvation, the priority is to supply food and attend to other needs, such as for water and shelter. The immediate goal of such interventions is to meet the basic needs and alleviate suffering. Once the situation has been stabilized, the aim is to move the beneficiaries to the next stage along the continuum, by providing support to help them recover their livelihoods and assets and to produce or purchase food. Interventions may take many forms, from direct production subsidies to public works programs with food or cash transfers, and can be combined with programs that support adequate consumption. The latter should aim to fill consumption gaps by increasing the opportunity to acquire sufficient food to meet dietary needs. These programs could take many forms, such as food fortification, supplementation, food parcel distribution and school feeding programs.

To ensure a progressive realization of food security, programs need to have clearly defined rules and regulations for beneficiary selection, benefit duration, conditionality (if applicable), exit strategies and monitoring and evaluation. Clear targets must be set, with measurable impact indicators. Such indicators should measure improvement in the food security continuum stages. For a program to be sustainable, and the

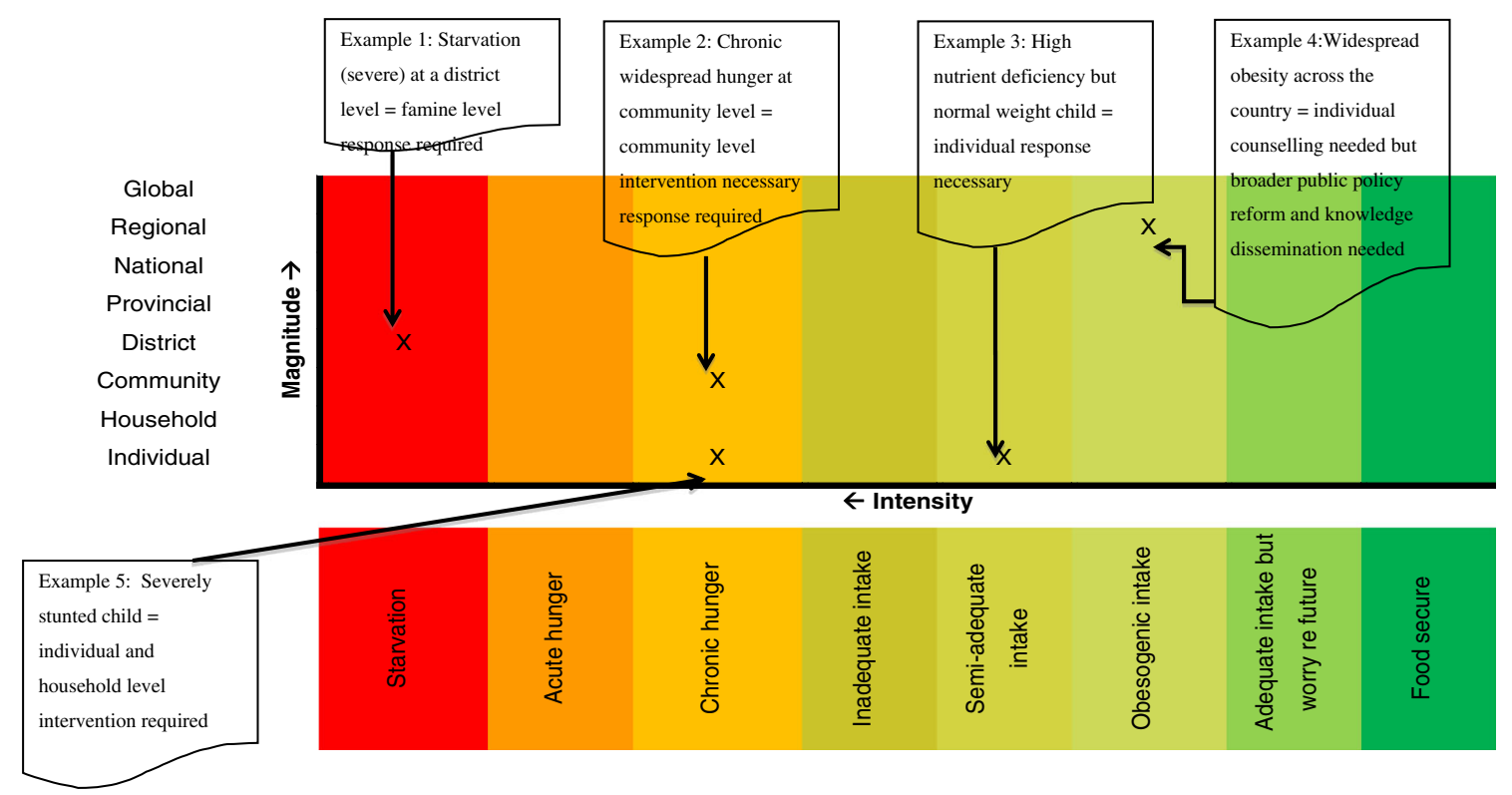

Fig. 3 Continuums of magnitude and intensity of food insecurity 
goal of long-term national food security to be achieved, program managers and beneficiaries must be given incentives to move progressively towards food security.

\section{Advantages of the continuum}

The food security continuum introduced in this paper brings together many aspects of food insecurity: the FAO's four dimensions (availability, accessibility, utilization and stability), nutritional inadequacy, the triple burden of hunger, nutrient deficiencies and obesity. It provides a comprehensive approach to understanding the experience and consequences of food insecurity and thus a basis for identifying food insecure individuals and households and designing programs appropriate to their situation. It makes it possible to identify individuals and households at various stages of food insecurity and estimate the severity of their problem. By showing us who they are and how many, it enables more accurate targeting of beneficiaries. This means that scarce resources can be used more efficiently. The continuum helps us to see the link between what we know of the experience of food insecurity and how it makes people behave (their coping strategies) and the typical symptoms they exhibit as a consequence of these strategies. It helps us to focus on each specific situation, taking into account differences in resource bases, livelihoods and individual or household decision-making. Its first big advantage is that it enables us to sidestep the complications introduced by theoretical disagreements about causality and interrelatedness and move more directly to acting to help the victims.

A second advantage of the continuum is that it provides concrete characterization of the affected individuals and households. We position victims at the various stages along the continuum according to universal quantitative measurements related to food security, such as population referenced anthropometric measures, and also according to their context, noting that coping strategies and asset bases are specific to communities and populations. By thus increasing accuracy, the continuum should reduce targeting errors (both inclusion and exclusion errors).

The third advantage is that it enables us not only to design interventions appropriate to the stage that the victims have reached but also to monitor the interventions effectively. The specific indicators identified for each stage along the continuum (at individual or household level, depending on the purpose of the intervention and its targeted beneficiaries) can be traced over time. Because a variety of indicators are possible for each stage, the selection of indicators can be determined by what data is collected regularly and adapted to rapid appraisal frameworks for emergency situations or to more impactfocused long-term monitoring and evaluation indicators. It would be possible to integrate the continuum indicators into the post-2015 Development Goals as it seems the Sustainable
Development Goals may include aspects of both hunger and poverty along with acknowledgement that individual nutritional adequacy is the foundation for achieving food security.

\section{Conclusion}

As observed in the introduction to this paper, understanding food insecurity requires inputs from different disciplines, but we should not allow academic disagreements to distract us from finding practical solutions. We should not waste time haggling over definitions and terminology and arguing about causes. We need a sound framework, based on the experiences and consequences of food insecurity that integrates the components of adequate food consumption, dietary quality relevant to the life cycle of each person and sustainable livelihoods to ensure future food security. While the food security continuum presented in this paper does not specify indicators, it offers a visual guide for more concerted effort to identify food insecurity in comparable ways across populations and monitor the course of interventions.

The food security continuum builds on our iterative understanding of food insecurity as a phenomenon. It categorizes levels of intensity of food insecurity and matches them with appropriate interventions at each stage. It brings convergence to the economic, social, environmental and political aspects of food insecurity and, by focusing on individual experience, it considers the right to food. It is a step towards designing appropriate policies and programs to respond to the plight of deprived individuals, households and communities. It can help us achieve the two essential goals of any program: first to attend to people's immediate needs, and second to help them build resilience in the face of stresses and shocks. It is a progressive, rights-based approach to food security, intended to help us move beneficiaries along the path towards food security.

Until recently, many famine interventions were initiated in response to the proportion of the population experiencing extreme starvation over a prolonged period on a scale that could not be ignored (Howe and Devereux 2004). The continuum is not meant to replace existing famine early warning systems or food security monitoring systems but rather to extend such efforts beyond relief operations towards a more integrated understanding of food security across the range of experiences. We must not wait until a food shortage becomes a significant humanitarian crisis before acting. The prevalence and scale of hunger and malnutrition worldwide is unacceptable. It requires a comprehensive approach that can assist national governments to achieve global development goals.

The continuum draws our attention to the less extreme manifestations of food insecurity that demand our ongoing rather than emergency attention. It enables us to visualize the triple burden of hunger, nutrient deficiencies and obesity in a comprehensive way. It provides a framework for focusing 
policy attention on the entire food system and anticipating the outcome of interventions and policies. Applying this comprehensive approach across the full range of experiences may help us avoid some of the unintended consequences of food security interventions such as the consumption changes that may accompany increased incomes in societies with easy access to cheap "obesogenic" foods (Pincock 2011) that encourage excessive weight gain.

To deal with all the stages along the food insecurity continuum demands a multi-sectoral commitment to working together with communities to realize their right to food and formulate food security action plans. Governments must provide a bundle of public goods to support progressive steps towards long-term household food security. In enabling us to measure and monitor food insecurity at different levels and thus improve targeting and intervention design, the continuum will also improve accountability for public and donor spending.

Open Access This article is distributed under the terms of the Creative Commons Attribution 4.0 International License (http:// creativecommons.org/licenses/by/4.0/), which permits unrestricted use, distribution, and reproduction in any medium, provided you give appropriate credit to the original author(s) and the source, provide a link to the Creative Commons license, and indicate if changes were made.

\section{References}

Alderman, H. (2009). The economic cost of a poor start to life. Journal of Developmental Origins of Health and Disease, 1(1), 19-25.

Alinovi, L., Mane, E., \& Romano, D. (2010). Measuring household resilience to food insecurity: An application to Palestinian households. In R. Benedetti, M. Bee, G. Espa, \& F. Piersimoni (Eds.), Agricultural survey methods. Chichester: Wiley.

Barrett, C. B. (2010). Measuring food insecurity. Science, 327, 825. doi: 10.1126/science. 1182768 .

Barrett, C. B., \& Headey, D. (2014). Measuring resilience in a risky world: Why, where, how and who? 2020 Conference Brief 1: Building Resilience for Food and Nutrition Security. Washington, DC: IFPRI (International Food Policy Research Institute).

Bhattacharya, J., Currie, J., \& Haider, S. (2004). Poverty, food insecurity, and nutritional outcomes in children and adults. Journal of Health Economics, 23, 839-862.

Browne, M., Ortmann, G. F., \& Hendriks, S. L. (2014). Developing a resilience indicator for food security monitoring and evaluation. Agrekon, 53(2), 25-46.

Caballero, B. (2005). A nutrition paradox: underweight and obesity in developing countries. New England Journal of Medicine, 352(15), $1515-1516$

Campbell, C. C. (1991). Food security: a nutritional outcome of a predictor variable? Journal of Nutrition, 121, 408-415.

Candel, J. L. (2014). Food security governance: a systemic literature review. Food Security, 6, 585-601.

Carlson, S. J., Andrews, M. S., \& Bickel, G. W. (1999). Measuring food insecurity and hunger in the United States: development of a national benchmark measure and prevalence estimates. Journal of Nutrition, 1129, 2. doi:10.1371/journal.pmed.1000101.
CFS (Committee on World Food Security). (2012). Report of the 39th session of the Committee on World Food Security (CFS), Rome, 1520 October 2012. Rome: CFS.

Coates, J. (2013). Build it back better: deconstructing food security for improved measurement and action. Global Food Security, 2, 188-194.

De Waal, A., \& Whiteside, A. (2003). New variant famine: AIDS and food crisis in southern Africa. Lancet, 362(9391), 1234-7.

Devereux, S. (2009). Why does famine persist in Africa? Food Security, $1,25-35$.

Dietz, W. H. (1995). Does hunger cause obesity? Pediatrics, 95, 766.

FAO (Food and Agriculture Organization). (1996). World food summit: Rome declaration on world food security. Rome: FAO.

Frongillo, E. A. (2013). Confronting myths about household food insecurity and excess weight. Cadernos de Saúde Pública, 29(2), 229-230.

Gross, R., \& Webb, P. (2006). Wasting time for wasted children: severe child under-nutrition must be resolved in non-emergency settings. The Lancet, 367(9517), 1209-1211. doi:10.1016/S0140-6736(06) 68509-7.

Headey, D., \& Ecker, O. (2013). Rethinking the measurement of food security: from first principles to best practice. Food Security, 5, 327343.

Hendriks, S. L. (2005). The challenges facing empirical estimation of food (in) security in South Africa. Development Southern Africa, 22(1), 103-123.

Hendriks, S. L. (2013). Will renewed attention and investment in African agriculture ensure sound nutrition? European Journal of Development Research, 25, 36-43.

Hendriks, S. L., \& Drimie, S. (2011). Chapter 7, global food crisis and African response: Lessons for emergency response planning. In D. S. Miller \& J. S. Rivera (Eds.), Comparative emergency management: Examining global and regional responses to disasters (pp. 153-173). Boca Raton: CRC/Taylor \& Francis.

Howe, P., \& Devereux, S. (2004). Famine intensity and magnitude scales: a proposal for an instrumental definition of famine. Disasters, 28(4), $353-373$

Lang, T., \& Barling, D. (2012). Food security and food sustainability: reformulating the debate. Geographical Journal, 178(4), 313-326.

Løvendal, C. R., \& Knowles, M. (2005). Tomorrow's hunger: A framework for analyzing vulnerability to food insecurity. Agriculture and Development Economics Division ESA working paper, 05-07. Rome: Food and Agriculture Organization of the United Nations.

Masset, E. (2011). A review of hunger indexes and methods to monitor country commitment to fighting hunger. Food Policy, 36, S102S108.

Maxwell, D. G. (1996). Measuring food insecurity: the frequency and severity of "coping strategies". Food Policy, 21(3), 291-303.

Maxwell, D., Ahiadeke, C., Levin, C., Armar-Klemesu, M., Zakariah, S., \& Lamptey, G. M. (1999). Alternative food-security indicators: revisiting the frequency and severity of "coping strategies". Food Policy, 24, 411-429.

McMillan, T. (2014). The new face of hunger: Why are people malnourished in the richest country on Earth? National Geographic, August 2014. www.nationalgeographic.com/foodfeatures/hunger/. Accessed 28 August 2014.

Pangaribowo, E. H, Gerber, N., \& Torero, M. (2013). Food and nutrition security indicators: A review. Working paper no. 108. Zentrum für Entwicklungsforschung (ZEF) Working Paper Series, Department of Political and Cultural Change, Center for Development Research, University of Bonn.

Pincock, S. (2011). Boyd Swinburn: combating obesity at the community level. Lancet, 378(9793), 761. doi:10.1016/S0140-6736(11)61364-0.

Pinstrup-Andersen, P. (2009). Food security: definition and measurement. Food Security, 1, 5-7.

Popkin, B. M., Adair, L. S., \& Ng, S. W. (2012). Now and then: The global nutrition transition: the pandemic of obesity in developing 
countries. Nutrition Review, 70(1), 3-21. doi:10.1111/j.1753-4887. 2011.00456.x.

Radimer, K. L., Olson, C. M., \& Campbell, C. C. (1990). Development of indicators to assess hunger. Journal of Nutrition, 120, 1544-1548.

Renzaho, A. M. N., \& Mellor, D. (2010). Food security measurement in cultural pluralism: missing the point or conceptual misunderstanding? Nutrition, 26, 1-9.

Riches, G. (1998). First world hunger: Food security and welfare politics. New York: Palgrave Macmillan.

Rose, D., Basiotis, P. P., \& Klein, B. W. (1995). Improving federal efforts to assess hunger and food insecurity. Food Review, 18, 18.

Rugalema, G. (2007). Coping or struggling? a journey into the impact of HIV/AIDS in southern Africa. Review of African Political Economy, 27(86), 537-545. doi:10.1080/03056240008704488.

Sarlio-Lähteenkorva, S., \& Lahelma, E. (2001). Food insecurity is associated with past and present economic disadvantage and body mass index. Journal of Nutrition, 1(131), 2880-2884.

Sen, A. (1981). Poverty and famines: An essay on entitlement and deprivation. Oxford: Clarendon.

Stevens, G. A., Singh, G. M., Lu, Y., Danaei, G., Lin, J. K., Finucane, M. M., Bahalim, A. N., McIntire, R. K., Gutierrez, H. R., Cowan, M., Paciorek, C. J., Farzadfar, F., Riley, L., Ezzati, M., \& the Global Burden of Metabolic Risk Factors of Chronic Diseases Collaborating Group (Body Mass Index). (2012). National, regional, and global trends in adult overweight and obesity prevalence. Population Health Metrics, 10, 22. doi:10.1186/1478-7954-10-22.

Te Lintelo, D. J. H., Haddad, L. J., Lakshman, R., \& Gatellier, K. (2014). The Hunger and Nutrition Commitment Index (HANCI 2013): Measuring the political commitment to reduce hunger and under nutrition in developing countries. Brighton: Institute for Development Studies, University of Sussex.

Townsend, M. S., Peerson, J., Love, B., Achterberg, C., \& Murphy, S. P. (2001). Food insecurity is positively related to overweight in women. Journal of Nutrition, 131(6), 1738-1745.

UNICEF, WHO \& World Bank (United Nations' Children's Fund, World Health Organization \& World Bank). (2013). Joint UNICEFWHO - The World Bank Child Malnutrition Database: Estimates for 2012 and launch of interactive data dashboards. www.who.int/ nutgrowthdb/jme_2012_summary_note_v2.pdf?ua=1. Accessed 11 September 2014.

UNSCN (United Nations Standing Committee on Nutrition). (2012). Coming to terms with terminology: Food security, nutrition security, food security and nutrition, food and nutrition security. Rome: CFS (Committee on World Food Security). www.fao.org/fsnforum/sites/default/files/file/Terminology/
MD776(CFS__Coming_to_terms_with_Terminology).pdf. Accessed 26 August 2014.

Vaitla, B., Devereux, S., \& Swan, S. H. (2009). Seasonal hunger: a neglected problem with proven solutions. PLoS Medicine, 6(6), e1000101.

Webb, P., Coates, J., Frongillo, E. A., Lorge Rogers, B., Swindale, A., \& Bilinsky, P. (2006). Measuring household food insecurity: why it's so important and yet so difficult to do. Journal of Nutrition, 136, 1404S-1408S.

WHO (World Health Organization). (2010). Nutrition landscape information system: Country profile indicators. Interpretation guide. Geneva: WHO.

Wunderlich, G. S., \& Norwood, J. L. (2006). Food insecurity and hunger in the United States: An assessment of the measure. Washington, DC: Panel to Review the US Department of Agriculture's Measurement of Food Insecurity and Hunger, Committee on National Statistics, Division of Behavioral and Social Sciences and Education, National Research Council of the National Academies of Science. National Academies Press.

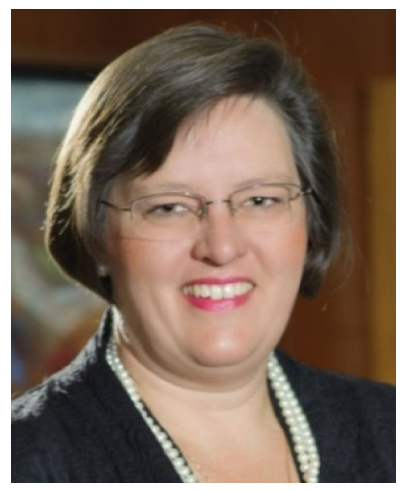

Prof Sheryl Hendriks is the CoDirector of the Department for Science and Technology and the National Research Foundation Centre of Excellence in Food Security and founding Director of the Institute for Food Nutrition and Well-being (IFNuW) at the University of Pretoria. She holds a $\mathrm{PhD}$ in Agricultural Economics. Prof Hendriks is the immediate Past President of the Agricultural Economics Association of South Africa (AEASA) and was the first female President of the Association. She is one of only three experts from Africa appointed to the Committee for World Security (CFS) High Level Panel of Experts on Food Security and Nutrition (HLPE) and is currently serving a second period of appointment on the Panel. She led the African Union and NEPAD's Comprehensive African Agricultural Development Programme's (CAADP) Food Security initiatives between 2006 and 2010. Her research focuses on household food security, measurement and monitoring of food security and food security policy. She has graduated students from 18 African countries, contributing significantly to developing the food security capacity in the continent and South Africa. 